\title{
International Journal of Health Sciences
}

Available online at http://sciencescholar.us/journal/index.php/ijhs

Vol. 2 No. 3, December 2018, pages: 1 10

e-ISSN: 2550-696X, p-ISSN: 2550-6978

https://doi.org/10.29332/ijhs.v2n3.198

\section{Obesity: Problem to Consider in Public Health}

\author{
CrossMark \\ Thalia Fuentes Leyva a, Yostin Raul Menendez Mendoza b, Britany Mirella Palma Alcivar c, Ariana \\ Milene Arias Caballero ${ }^{d}$
}

Article history: Received 5 May 2018, Accepted: 30 August 2018, Published: 17 September 2018

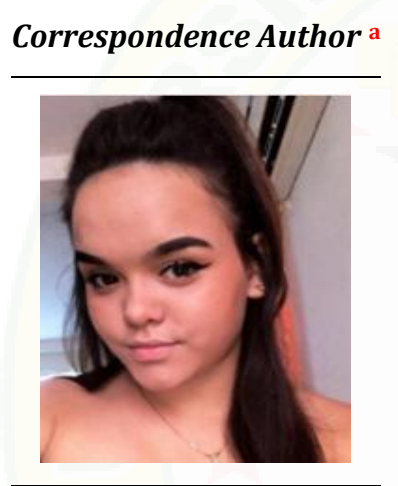

Keywords

Habits;

Inadequate eating;

Lifestyle;

Obesity;

People health;

\begin{abstract}
Overweight is an increase in body mass; Obesity is the increase in the size or quantity of fat cells sufficient to damage the health of the individual. It is the world millennium pandemic, which affects all types of population, does not discriminate between age, race, sex, social position or religion, according to the World Health Organization is considered obese to people with a higher body mass index or equal to $30 \mathrm{~kg} / \mathrm{m}^{2}$. It has been shown that good advice can be remedied with this acute physical problem and that often leads to self-esteem and mental problems. The work is supported in the investigation of the phenomenon of obesity, its causes, and consequences for human health in the parish March 12, in the city of Portoviejo in the province of Manabí. The results of a survey carried out on a sample of 97 adults residing in the parish are exposed, showing the high level of obesity that exists in the population, as well as the inadequate eating habits and the sedentary lifestyle that accompanies this problem. Health. It is evident that the fundamental causes of obesity consist of a well-localized group of inadequate food practices and the lack of physical exercise, a situation that can be combated from social work where the factors and the society of the community can be compromised, aimed at reducing obesity levels and increasing the health of the population.
\end{abstract}

e-ISSN: 2550-696X, p-ISSN: 2550-6978 ${ }^{\circ}$ Copyright 2018. The Author. SS Journals Published by Universidad Técnica de Manabí. This is an open-access article under the CC BY-SA 4.0 license (https://creativecommons.org/licenses/by-sa/4.0/) All rights reserved.

\section{Contents}

Abstract 1

1. Introduction

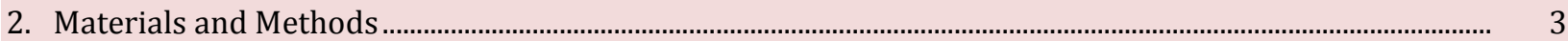

a Universidad de Guayaquil, Ecuador

b Universidad de Guayaquil, Ecuador

c Universidad de Guayaquil, Ecuador

d Universidad Tecnica de Manabi, Portoviejo Ecuador 


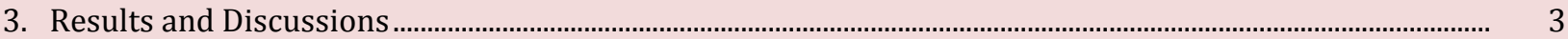

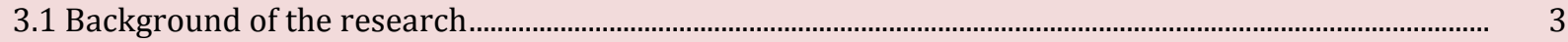

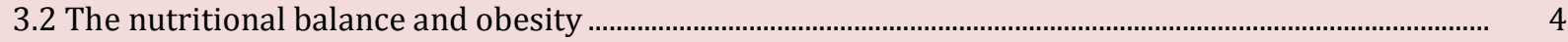

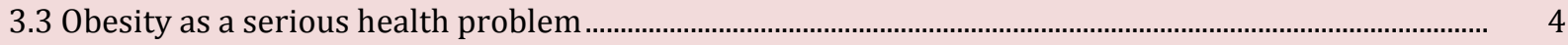

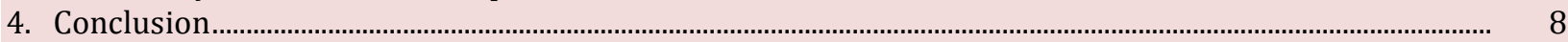

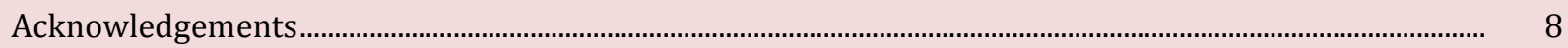

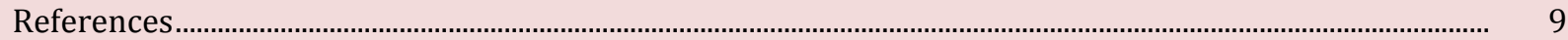

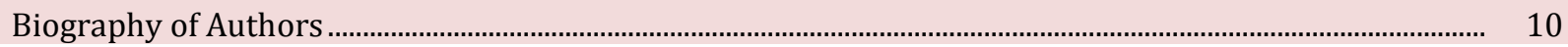

\section{Introduction}

Obesity is the excess of adipose tissue, which manifests itself with an inadequate weight. The development of obesity, throughout the different years in a person's life, has been linked to multiple causes. Only occasionally it is possible to define a single predominant cause that has set in motion the energy imbalance.

Currently, obesity is a serious health problem that becomes a precursor to other diseases, constituting one of the main challenges for development in the XXI century. It is proven that obesity is associated with diseases such as diabetes, high blood pressure, dyslipidemias (alteration of fats), cardiovascular diseases, gout, osteoarthrosis, sleep apnea syndrome, fatty liver and certain types of cancer, which are among the major health complications that cause death in people who suffer from it. The rapid increase in the incidence of diseases associated with obesity disproportionately affects poor and disadvantaged populations, aggravating health inequalities.

In Ecuador, obesity is a health problem that is a concern of health authorities and social factors, especially in some communities that are usually more affected than others. In the parish of March 12 in the city of Portoviejo, community authorities have expressed their concern about the number of obese citizens residing in it, especially their concern is to know what are the reasons for this phenomenon and what would be the consequences of this situation, of not finding an alternative solution. It is worrying that the health levels of the adult population that suffers from obesity have a relapse with other associated diseases, which would bring higher expenses at the socio-family level of the community.

The importance of treating obesity as a serious health problem, part of the fact that at the same time is a cause for other health problems that threaten the quality of life of the population and even against their lives, making it more expensive the family and social economy, having to ensure a greater supply of medicines and specialized medical attention (Tjiang \& Sidiartha, 2018). As important as epidemiological data is the need to produce in society and among professionals a conceptual revolution, a profound change in mentality that leads to consider obesity as a chronic disease, and to propose coherent medical strategies for multidisciplinary treatment. Obesity requires a change of paradigm and a sustainable strategy, it needs to be rescued as a real health problem and take its management to the only responsible field: that of evidence-based medicine away from the para-medicine and the scientific business.

Moving in the response field in the treatment of obesity means correctly diagnosing all obese patients and proposing appropriate treatment strategies, as with any other chronic disease: treatments that are maintainable in the medium and long-term, that do not cause harmful side effects and that have told the complex reality of eating and energy homeostasis. It implies a sustainable change in the environmental conditions that allow the phenotypic expression of obesity, that is, a change in lifestyle in the three fundamental axes of action: food, physical exercise and attitudes towards food, to which Drugs and surgery are added to patients and/or times when it is indicated (Wiardani, et al., 2018). The project aims to offer a concrete result aimed at knowing the main causes and consequences of obesity in adults of the Parish March 12 of the city of Portoviejo, which allows anticipating the successful diagnosis and treatment of associated diseases.

In such a way that professionals can be in a position to make a selection, diversification and prioritization of approaches from health work and a better study of potentially useful agents, tasks in which multidisciplinary and translational research is crucial and in which systematic and comprehensive teaching is intended to contribute. The objective of the work is to expose the risks of inadequate nutrition and obesity as health problems that must be carefully attended. 


\section{Materials and Methods}

The research corresponds to the field work, which made it possible to obtain the greatest amount of information through direct contact with the adult population involved in the study. Also of an exploratory nature, because an approach was made to the problem of obesity and the consequences that derive from it, allowing to know the subject and gain familiarity with a situation that until now had not been studied. It is of the descriptive type because it has allowed describing the reality that the problem of obesity presents in the 12 de Marzo parish of the municipality of Portoviejo, all this has allowed to accumulate and process the necessary data. Also of the explanatory type because it manages to explain reasonably the causes that cause obesity in adults.

The research design is quali-quantitative, since a descriptive study is applied to determine the prevalence of overweight, obesity and associated risk factors; eating habits and physical activity, in the population, studied. The observation was applied as the primary method, which allowed to verify the scientific feasibility to develop the research. The descriptive method is, therefore, able to define, classify, catalog and characterize the problem related to the obesity of the population, its causes, and consequences. The deductive method that allowed to apply logical reasoning in the investigation, analyzing the most general situation to arrive at precise conclusions about the subject studied. The method of bibliographic review was applied, which included the study of 35 web pages related to the subject of obesity, human nutrition, and associated diseases, of which a total of 13 bibliographies were reported (Suiraoka, et al., 2017).

As a basic technique, a survey was applied to identify the risk factors that are influencing the population under study, for which a basic clinical analysis was planned for each person surveyed, which included the taking of temperature, body weight and the measurement of height.

For this, a group of instruments was used, among which are: a thermometer, a weight, and a graduated tape. In addition, the questionnaire of the survey, sheets of paper and pens were used. As a starting point, various reports were taken from the neighborhood and parochial council, as well as other information documents from the Decentralized Autonomous Council of the municipality of Portoviejo.

The universe was formed by the resident population of the parish March 12 of the city of Portoviejo, which has a total adult population of 20345 people, and a sample of 97 people was defined. For this, a population of 15,650 adults was considered and was determined by applying equation 1 (Larry \& Murray, 2005).

$$
\mathrm{n}=\frac{\left(Z^{2}\right)(P)(Q)(N)}{\left(Z^{2}\right)(P)(Q)(N)\left(e^{2}\right)}
$$

Where:

$\mathrm{n} \rightarrow$ Sample size

$\mathrm{Z} \rightarrow$ Level of confidence

$\mathrm{P} \rightarrow$ Probability of occurrence

$\mathrm{Q} \rightarrow$ Probability of non-occurrence

$\mathrm{N} \rightarrow$ Population or universe

$\mathrm{e} \rightarrow$ Acceptable limit of the sampling error

\section{Results and Discussions}

\subsection{Background of the research}

The history of obesity is ancient and dates back at least to the stone age, however, the meaning of this condition has varied in each epoch due to the influence of many factors, such as scientific, food, cultural, political, psychological, economic and religious. Food and nutrition are associated with symbolism that permeates all aspects of our culture. It has been said that the history of man is only understandable in the context of the history of food.

Leyva, T. F., Mendoza, Y. R. M., Alcivar, B. M. P., \& Caballero, A. M. A. (2018). Obesity: problem to consider in public health. International Journal of Health Sciences, 2(3), 1-10. https://doi.org/10.29332/ijhs.v2n3.198 
The first changes in eating habits occurred in prehistoric times when man began to produce his food instead of collecting it. In ancient Greece, Galen was one of the most dominant figures in the history of medicine. He identified two types of obesity: moderate and immoderate. The first was classified as natural and the second as morbid. In the Middle Ages, the Christian religion had a powerful influence on attitudes towards food and body weight. On the one hand, obesity was a gift from God (rare, since food was scarce and there were a lot of plagues), on the other, gluttony was considered a capital sin. In the eighteenth century, Fleming thought that corpulence was a disease due to several causes: an excess in the amount of food, especially the rich in oils, blood disorders and disorders in the evacuation.

The first case of pituitary obesity was discovered in the 19th century. It was suggested that certain types of obesity could result due to the increase in the number of cells. In the twentieth century continued with the development of knowledge about obesity. The stereotypes of beauty changed in Western countries after the Second World War. In the late 60's, the American model is characterized by its thinness, which meant a change in fashion patterns.

Currently, the Medical Sciences career of the Faculty of Medicine of the University of Guayaquil has been developing in recent years, research projects focused on improving the health of the population. The University of Guayaquil strives to achieve a community intervention that fosters a positive influence for the fulfillment of the plans drawn up by the state to achieve the Good Living of the Ecuadorian society, for which the execution of projects aimed at supporting public health, with an important participation of university students, among which is the medical career.

\subsection{The nutritional balance and obesity}

The nutritional imbalance, due to excess or lack of nutrients, affects health in different ways, generating disorders that can become serious. Understanding this is essential before suffering the risks of poor diet, as well as the immediate effects on health (Pérez, 2012), (Restrepo, 2016). All human beings need to consume certain types of foods and nutrients that contribute to physical and mental health. The nutritional imbalance, due to excess or lack of nutrients, affects the body in different ways, generating health disorders that can become serious. Understanding this is essential before suffering the risks of poor nutrition, as well as the immediate effects on health (FAO, 2014), (Bezzia, 2016).

Weight gain is one of the most visible consequences of poor diet. However, its seriousness is not a mere aesthetic issue, since obesity brings several problems: increased cholesterol, increased blood pressure, accumulation of fats in the arteries and the appearance of cardiovascular problems, as well as increased odds that we are affected by diabetes (Coronel, 2017).

\subsection{Obesity as a serious health problem}

Overweight and obesity are defined as an abnormal or excessive accumulation of fat that can be harmful to health. The body mass index (BMI) is a simple indicator of the relationship between weight and height that is frequently used to identify overweight and obesity in adults. It is calculated by dividing the weight of a person in kilos by the square of its size in meters ( $\mathrm{kg} / \mathrm{m} 2)(\mathrm{WHO}, 2018)$.

Obesity can be considered a serious health problem. Its consequences, as well as its causes, are many and diverse: cardiovascular problems (hypertension, diabetes, cholesterol, varicose veins, etc.); arthrosis: our skeleton suffers much more wear and tear because of the extra weight; respiratory distress and fatigue; greater tendency to cancer and; low self-esteem and its effects on the nervous system (sleep disturbances, anxiety, depression, etc.) (Arteaga, 2012).

Obesity generally decreases life expectancy. The obese, precisely because of the complications caused by obesity, live fewer years. The more complications the person has, the new problems are added to the ones they already had. This also implies the taking of more medications with their corresponding side effects (Sánchez, 2016), (Raimann, 2011).

The data and figures of the World Health Organization show (WHO, 2018) that since 1975, obesity has almost tripled worldwide; in 2016 more than 1,900 million adults 18 years of age and over were overweight, 
of which more than 650 million were obese; in 2016 itself, 39\% of adults aged 18 or over were overweight, $13 \%$ were obese and 41 million children under five were overweight or obese; The majority of the world's population lives in countries where overweight and obesity claim more lives than people who are underweight.

Obesity is often associated with other diseases that not only worsen the quality of life of patients, but also aggravate their health status, having become one of the preventable diseases that cause more deaths annually (CMED, 2015).

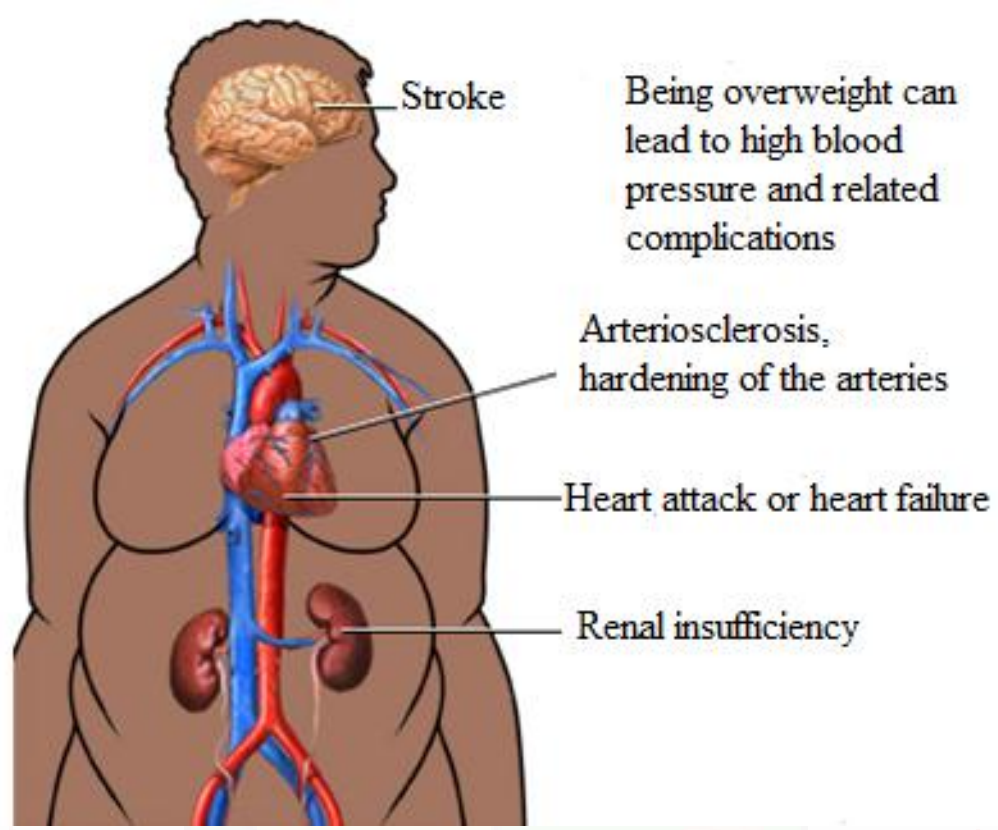

Figure 1. shows a diagram showing the diseases associated with obesity Source: (Tango, 2017)

\section{Localized and extracted by the author of the titration work}

Heart disease arises at first due to the formation of the so-called "atheroma plaques", which are accumulations of fatty matter adhered on the inner side of the coronary arteries, which are where nutrients and oxygen pass to the heart. Under these conditions increases the possibility of suffering a lack of oxygen and over time, it becomes angina. In addition, when body mass increases, the cardiac effort necessary to meet the body's needs also increases, which considerably worsens heart failure (Sala, 2018).

An obese or overweight person is more likely to suffer high blood pressure than those within a normal weight. Sleep apnea is another of the serious health problems that are linked to obesity and consists of a disorder that causes momentary stops of breathing continuously during sleep. It originates due to a momentary blockage of the passage of air through the upper airway (Room, 2018). Diabetes is a disease that occurs with high blood sugar levels (glycemia) due either to the lack of insulin production in the pancreas (Type 1 Diabetes) or to the peripheral resistance to insulin action due to overweight. (Type 2 diabetes). In turn, diabetes is a frequent cause of premature death, heart disease, stroke or blindness. A really impressive fact is that $90 \%$ of diabetic people are type 2 (Sala, 2018).

Some types of cancer are associated with patients who have obesity with a BMI greater than 40 , where there is a risk (almost 50\%) of getting cancer of the esophagus, colon, rectum, liver, gallbladder, pancreas, kidney, breast and uterus (Lopez \& González, 2001). Degenerative osteoarthritis is a widespread disease that mainly affects the knees, hips, and spine (especially the lower back). Obesity causes an excess of load on the joints and joint degeneration consequently (Sala, 2018).

Leyva, T. F., Mendoza, Y. R. M., Alcivar, B. M. P., \& Caballero, A. M. A. (2018). Obesity: problem to consider in public health. International Journal of Health Sciences, 2(3), 1-10. https://doi.org/10.29332/ijhs.v2n3.198 
Dyslipidemia is an abnormal increase in the concentration of lipid levels (both cholesterol and triglycerides) that carry lipoproteins in the blood. That is to say, an alteration of the levels of lipids in the blood. As a result, there is an increase in total cholesterol and a decrease in HDL cholesterol (good cholesterol) (Rojas, 2014). Infertility is another of the health problems that are associated with obesity and can produce alterations in the menstrual cycle related to female infertility. In addition, obesity is also an added risk to pregnancy, since it can facilitate the onset of gestational diabetes and produce a higher incidence of cesarean deliveries (León, 2017). But all the comorbidities associated with obesity remit by $80 \%$ or even disappear recovering normal weight. In addition, returning to the ideal weight produces an increase in the half-life of 10 years and with a better quality of life (Tango, 2017).

During the investigation, 97 surveys were applied to the population, where among others the following results:

Could be verified It was found that 3\% of the people surveyed weigh less than $50 \mathrm{~kg}$; $9 \%$ behave between $51 \mathrm{~kg}$ and $70 \mathrm{~kg} ; 18 \%$ have a weight between $71 \mathrm{~kg}$ and $80 \mathrm{~kg} ; 54 \%$ have a weight between $81 \mathrm{~kg}$ and $90 \mathrm{~kg}$ : $10 \%$ have a weight between $91 \mathrm{~kg}$ and $100 \mathrm{~kg}$ and; $6 \%$ behaves with a weight greater than $100 \mathrm{~kg}$. It can be clearly seen that most of the adults surveyed are between $81 \mathrm{~kg}$ and $90 \mathrm{~kg}$ and if the higher weights are considered it can be verified that $70 \%$ of the surveyed population has a weight above $81 \mathrm{~kg}$.

At the same time, it was found that $1 \%$ of the people surveyed have a height of less than $100 \mathrm{~cm}$; $\%$ have stature between 101 and $140 \mathrm{~cm} ; 48 \%$ between 141 and $150 \mathrm{~cm} ; 43 \%$ between 151 and $160 \mathrm{~cm}$ : 2\% presents between 161 and $170 \mathrm{~cm}$ and; $1 \%$ behaves in more than $170 \mathrm{~cm}$, being able to appreciate that the average height is between 141 and $160 \mathrm{~cm}$, where $91 \%$ of the respondents are concentrated. This data, combined with the weight, will allow the determination of the BMI body mass index, and from the analysis of this, it will be possible to estimate the obesity level of the population surveyed in the parish of March 12 in the city of Portoviejo.

The information obtained during the survey allowed to determine the BMI of the surveyed population, which was calculated using equation (2) (Moya, 2018). In Table 1 shows the statistical results related to the study of the body mass index.

$$
\begin{aligned}
& B M I=P c \cdot E_{2} \\
& \text { Where: } \\
& \text { BMI } \rightarrow \text { body mass index } \\
& \text { Pc } \rightarrow \text { body weight }(\mathrm{kg}) \\
& \text { E2 } \rightarrow \text { body height }\left(\mathrm{m}^{2}\right)
\end{aligned}
$$

Table 1

Measurement of BMI

\begin{tabular}{lcc}
\hline \multicolumn{1}{c}{ Body mass index (BMI) } & Amount & Percentage (\%) \\
\hline Less than 25 & 1 & 1 \\
From 25 to 30 & 7 & 7 \\
From 31 to 35 & 16 & 17 \\
From 35 to 40 & 38 & 39 \\
More than 40 & 35 & 36 \\
Total & 97 & 100 \\
\hline
\end{tabular}

Source: Statistical data on the results of the surveys

Prepared by: Author of the titration work

Regarding the dietary habits, the survey showed that $22 \%$ of the people said that they usually eat breakfast with coffee, milk, tea, chocolate, cocoa, yogurt, etc.; $20 \%$ with bread, toast, cookies, cereals, pastries, with or without butter, oil, etc.; $15 \%$ with fruit, juice, etc., $30 \%$ with Eggs, cheese, cold cuts, bacon or sausages: $46 \%$ with other types of food and / or drinks and; 33\% do not usually eat breakfast. All this indicates that most of the people surveyed have in some cases a considerable overfeeding, while others do not manage to be adequately nourished, which is significantly influencing the overweight they are. 
Regarding the hours of sleep, it was found that 3\% of people reported sleeping less than 4 hours daily; $32 \%$ say sleep between 4 and 6 hours; 44\% state that they sleep between 6 and 8 hours and 16\% sleep more than 8 hours. This information corroborates that most of the people surveyed associate strong overfeeding with a wide sleep habit. In relation to the sedentary lifestyle it was found that $36 \%$ of the people said that the main activity in their workplace is sitting most of the day; $40 \%$ say that they remain standing for most of the day without making large displacements or efforts; $14 \%$ state that walking, carrying some weight, making frequent trips that do not require great physical effort and; $9 \%$ performing tasks that require great physical effort.

In relation to the daily routine it was verified that $28 \%$ do not perform any physical activity; $32 \%$ do some physical or sports activity less than once a month; $13 \%$ do some physical or sports activity once or several times a month, but less than once a week; $27 \%$ perform some physical or sports activity once or several times a week. The results of the survey show that most of the people surveyed neglect to carry out an adequate physical activity, which is manifested in the performance of their work and in the routine of daily life.

In relation to the state of health, it was found that $1 \%$ of people say that they have a very good health; $9 \%$ state that it is good; $59 \%$ state that it is regular; $23 \%$ say it is bad; $8 \%$ say it is very bad. The previous results show that most people show deterioration in health status. In the 97 surveys conducted, 378 health problems and diseases are referred to, which corresponds to practically four diseases per person surveyed. Figure 2 shows the graphical results of the behavior of health problems and diseases declared by the 97 people surveyed.

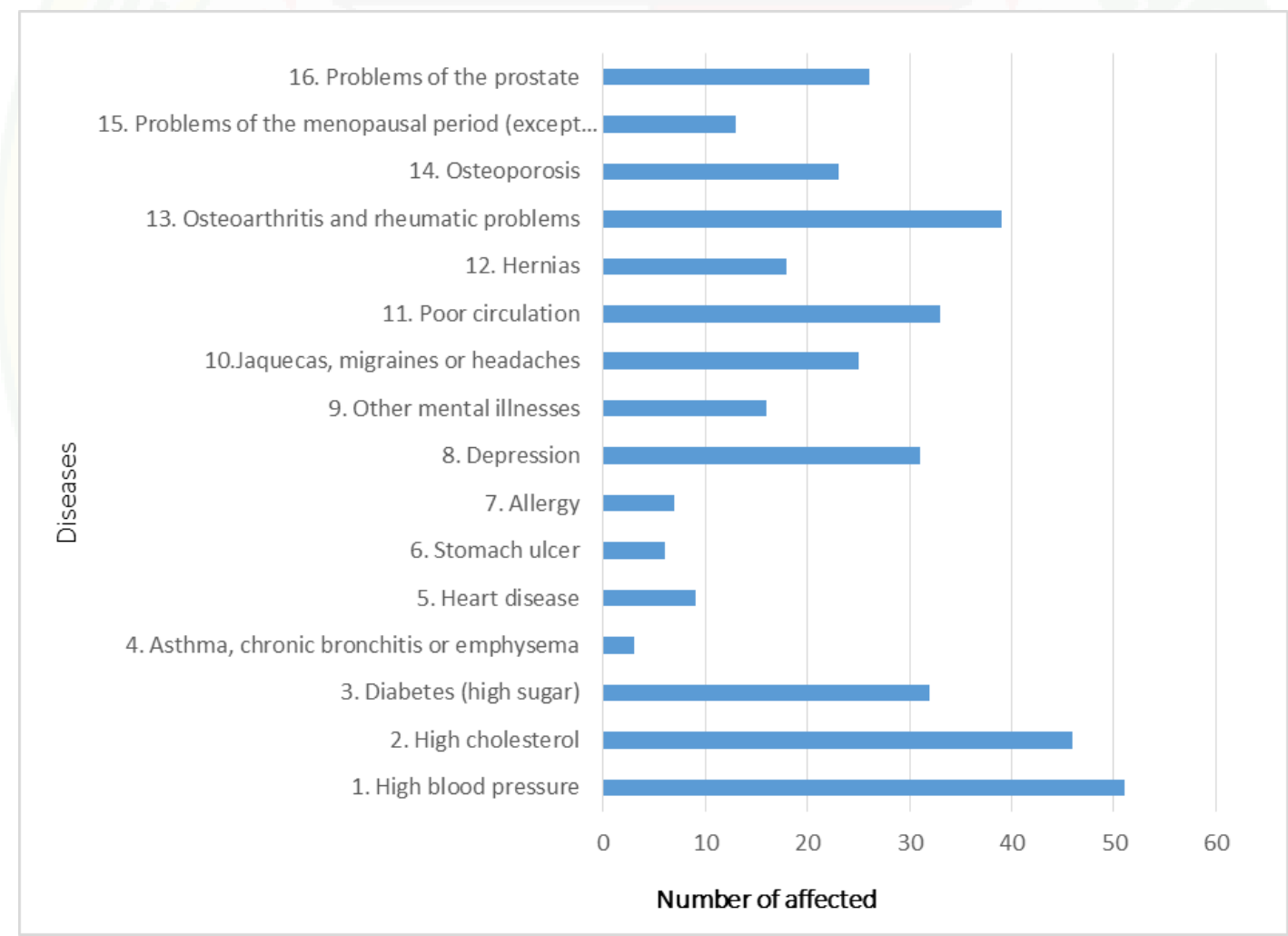

Figure 2. Graphical results of the behavior of health problems and diseases Source: Statistical data on the results of the surveys

Prepared by: Author of the titration work

The investigation showed that in the adult population of the parish of March 12 in the city of Portoviejo, there is a tendency to suffer from obesity on the part of the majority of the population.

It was found that the tendency to obesity is motivated by poor nutrition habits characterized by overfeeding and a sedentary lifestyle that encompasses work activities and the daily routine of the majority of

Leyva, T. F., Mendoza, Y. R. M., Alcivar, B. M. P., \& Caballero, A. M. A. (2018). Obesity: problem to consider in public health. International Journal of Health Sciences, 2(3), 1-10. https://doi.org/10.29332/ijhs.v2n3.198 
the population. Obesity has its origin in the practice of bad habits of nutrition accompanied by a sedentary life, which implies the need to carry out a wide social work of the community factors in the interest of modifying bad eating habits and sedentarism, achieving reduce obesity and its risks.

\section{Conclusion}

It was found that obesity problems are creating various health problems in people who suffer from it, which causes loss of time and interruptions in the normal activities that these people develop. It was found that the obese people who were surveyed are aware that the health problems they have are basically due to obesity, so they expressed the will to do everything possible to take the necessary measures to reduce the risks of obesity.

Acknowledgments

The authors acknowledge to the reviewer and editor of the International Journal of Health Sciences for their support, valuable time, and advice. 


\section{References}

Arteaga, LA (2012). Overweight and obesity as a health problem. Medical Journal Las Condes Clinic. Volume 23, Issue 2, March 2012, 145-153.

Bezzia (2016). Consequences of an unbalanced diet. Retrieved on July 16, 2018. Available at:

CMED. (2015). Obesity and its associated diseases. Medical Center - Surgical Digestive Diseases, Consulted on August 20, 2018.

Coronel, CSJ (2017). Proposal to improve the nutritional imbalance in the typical dishes based on fish in the Lambayeque region. Private University Juan Mejía Baca. University Career in Hotel Management, Tourism, Ecotourism and Gastronomy, Chiclayo.

FAO. (2014). Nutrition and health. Instructional material edited by FAO. UN, Available at:

Larry, \& Murray. (2005). Determination of the sample in a known population. Methodology of Scientific Research.

León, J. (2017). 5 diseases associated with obesity that could be improved with a single surgery. University of Los Andes Clinic.

López, AJC, \& González, GLT (2001). Diseases associated with obesity. > Journals> Journal of Endocrinology and Nutrition> Year 2001, No. 2.

Moya, R. (2018). Consulted the 20 of gosto of 2018.

Pérez, GA (2012). Analysis of the nutritional imbalance: intake higher than the needs. Reduca (Nursing, Physiotherapy and Podiatry) End of Degree Work Series. 4 (1): 276-316, 2012. ISSN: 1989-5305.

Raimann, X. (2011). Obesity and its complications REV. MED. CLIN. CONDES - 2011; 22 (1), 20-26.

Restrepo, P. (2016). Nutritional imbalances Retrieved on July 15, 2018. Available at:

Rojas, B. (2014). 23 dangerous diseases that causes obesity. Publímetro Science, Consulted on August 23, 2018.

Room, C. (2018). Diseases associated with obesity. Chiron Health Hospital. Valencia. Spain.

Sánchez, MFJ (2016). Obesity is a serious public health problem. Annals of the Royal National Academy of Pharmacies, Vol. 82 (2016). ISSN (Online) 1697-4298 6-26.

Suiraoka, I. P., Duarsa, D. P. P., Wirawan, I. D. N., \& Bakta, I. M. (2017). Perception of Parents, Teachers, and Nutritionist on Childhood Obesity and Barriers to Healthy Behavior: A Phenomenological Study. International Journal of Health Sciences (IJHS), 1(2), 1-11.

Tjiang, N., \& Sidiartha, I. G. L. (2018). Lipid profile in obese children with and without insulin resistance. International Journal of Health Sciences (IJHS), 2(2), 9-17.

WHO. (2018). Obesity and overweight. World Health Organization. Accessed July 17, 2018. Available at:

Wiardani, N. K., Adiatmika, I. G. P., Paramita, D. P., \& Tirtayasa, K. (2018). Adult women perception towards obesity and its intervention strategies in the community. International Journal of Health Sciences, 2(2), 4660 .

Leyva, T. F., Mendoza, Y. R. M., Alcivar, B. M. P., \& Caballero, A. M. A. (2018). Obesity: problem to consider in public health. International Journal of Health Sciences, 2(3), 1-10. https://doi.org/10.29332/ijhs.v2n3.198 


\section{Biography of Authors}

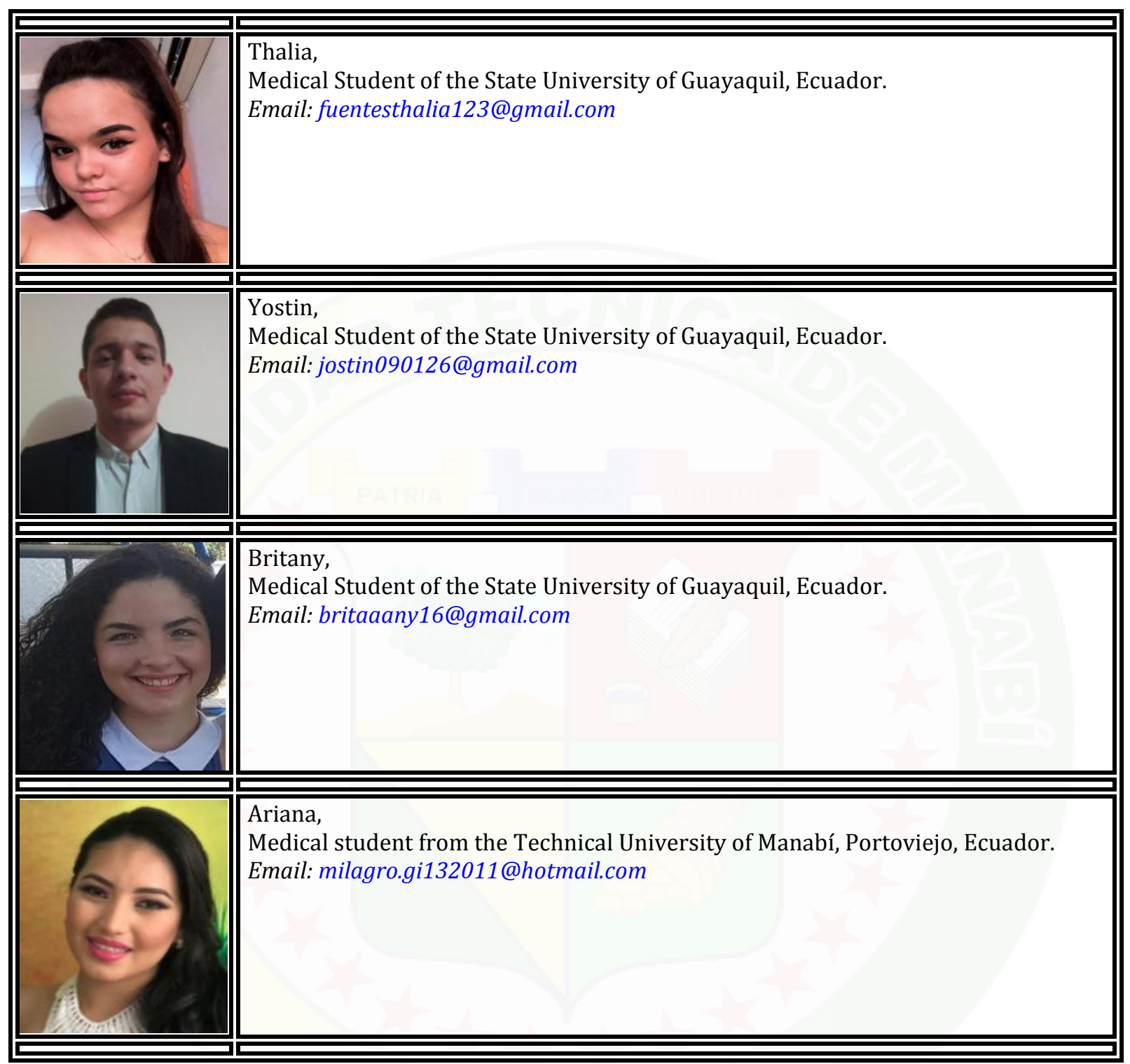

